\title{
Chemical abundances in seven galactic planetary nebulae ${ }^{\star}$
}

\author{
A. C. Krabbe and M. V. F. Copetti
}

\begin{abstract}
Laboratório de Análise Numérica e Astrofísica, Departamento de Matemática, Universidade Federal de Santa Maria, 97119-900 Santa Maria, RS, Brazil

e-mail: angela@lana.ccne.ufsm.br
\end{abstract}

Received 27 August 2005 /Accepted 1 December 2005

ABSTRACT

An observational study of chemical abundances in the galactic planetary nebulae NGC 1535, NGC 2438, NGC 2440, NGC 3132, NGC 3242, NGC 6302, and NGC 7009 based on long-slit spectra of high signal-to-noise ratio in the 3100 to $6900 \AA$ range is presented. We determined the $\mathrm{N}, \mathrm{O}, \mathrm{Ne}, \mathrm{S}$, and $\mathrm{Cl}$ abundances from collisionally excited lines and the $\mathrm{He}$ and $\mathrm{O}^{++}$abundances from recombination lines. The $\mathrm{O}^{++} / \mathrm{H}^{+}$ estimates derived from recombination lines are about a factor of four and two higher than those derived from forbidden lines for NGC 7009 and NGC 3242, respectively. Spatial profiles of $\mathrm{O}^{++} / \mathrm{H}^{+}$abundance from O II permitted lines and from [O III] forbidden lines were obtained for the planetary nebula NGC 7009. The differences between $\mathrm{O}^{++} / \mathrm{H}^{+}$derived from recombination and from forbidden lines present smooth variations along the nebular surface of NGC 7009, with the differences decreasing from the center to the edges of the nebula. If these abundance differences are explained by the presence of electron temperature fluctuations, quantified by the parameter $t^{2}$, a value of about $t^{2}=0.09$ is required for NGC 3242 and NGC 7009.

Key words. ISM: planetary nebula: general - ISM: abundances

\section{Introduction}

Almost all the determinations of abundances of heavy elements in HII regions and planetary nebulae published up to now are based on the analysis of collisional excited emission lines, which depend exponentially on electron temperature. This fact makes necessary the use of precise determinations of electron temperature to obtain reliable estimates of ionic abundances. On the other hand, recently it has been possible to determine abundances of heavy elements from recombination lines, which have the advantage of being weakly dependent on the electron temperature and in principle can be reliable indicators of chemical abundances. However, these lines are very faint, about $10^{3}-10^{4}$ times fainter than the strong forbidden lines, and thus are very difficult to detect and measure, mainly in objects with low surface brightness.

A common result reported in the literature is that the ionic abundances derived from recombination lines are systematically higher than those obtained from forbidden lines. These discrepancies can be very large, as for example, the factor of 10 found by Liu et al. (2000) in the CNO abundances for the planetary nebula NGC 6153. One potential explanation to these discrepancies would be the presence of temperature fluctuations inside of H II regions and planetary nebulae (Peimbert 1967). However, the observed values of electron temperature fluctuations have been lower than the ones necessary to

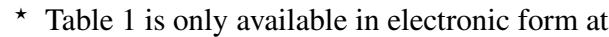
http://www. edpsciences.org
}

reconcile the abundances derived from forbidden and permitted lines (Liu 1998; Rubin et al. 2002; Krabbe \& Copetti 2002; Rubin et al. 2003; O'Dell et al. 2003; Krabbe \& Copetti 2005). Other solution that was suggested by Liu et al. (2000) would be the presence inside the nebula of hydrogen deficient clumps with high density and rich in heavy elements. A support for this hypothesis could arise from spatial profiles of abundances of heavy metals determined from recombination lines and forbidden lines in nebulae. However, only for the planetary nebulae NGC 6153 (Liu et al. 2000) and NGC 6720 (Garnett \& Dinerstein 2001) has such a study been done to date.

In our previous paper (Krabbe \& Copetti 2005, hereafter Paper I), we presented a study on the spatial variation of electron density and temperature in a sample of galactic planetary nebulae. In the present paper we used the Paper I data to determine the ionic and total abundances of $\mathrm{He}, \mathrm{N}, \mathrm{O}$, $\mathrm{Ne}, \mathrm{S}$, and $\mathrm{Cl}$ in the planetary nebulae NGC 1535, NGC 2438, NGC 2440, NGC 3132, NGC 3242, NGC 6302, and NGC 7009. A comparison between the spatial profiles of $\mathrm{O}^{++} / \mathrm{H}^{+}$derived from forbidden and recombination lines in the planetary nebula NGC 7009 is also given. Section 2 describes the data utilized and the adopted procedures for determination of total and ionic abundances. The results and discussions are presented in Sect. 3 and the conclusions are given in Sect. 4.

\section{Data analysis}

The current paper is based on long slit spectrophotometry data in the range of 3100 to $6900 \AA$ obtained on January, 
July and December 2002 with the Boller \& Chivens spectrograph attached to the $1.52 \mathrm{~m}$ telescope of the European Southern Observatory (ESO), Chile; and on September 1994 and May 2002 with the Cassegrain spectrograph of the $1.6 \mathrm{~m}$ telescope at the Laboratório Nacional de Astrofísica (LNA), Brazil. The slits used have entrances on the plane of sky of $2^{\prime \prime} \times$ $250^{\prime \prime}$ for the observations at ESO and $2^{\prime \prime} \times 320^{\prime \prime}$ for the observations at LNA. We used a Loral CCD of $2688 \times 512$ pixels at ESO and at LNA we used a SITe CCD of $1024 \times 1024$ pixels on May 2002 and an EEV CCD of $800 \times 1024$ pixels on September 1994. We used a grid of 1200 grooves $\mathrm{mm}^{-1}$ at LNA and at ESO we used a grid of 2400 grooves $\mathrm{mm}^{-1}$ during the January and July runs and a grid of 1200 grooves $\mathrm{mm}^{-1}$ during the December run. The spatial scale was $0.82^{\prime \prime} \mathrm{pxl}^{-1}$ for the Loral CCD, $0.90^{\prime \prime} \mathrm{pxl}^{-1}$ for the EEV CCD, and 1.0" $\mathrm{pxl}^{-1}$ for the SITe CCD. The spectra obtained had a spectral resolution of $1.5 \AA$ and $3.0 \AA$ for the observations at ESO and $2.8 \AA$ for the observations at LNA, measured as the full-width-at-half-maximum $F W H M$ of the emission lines of the comparison lamps. In Paper I, we described the observations and the data reduction procedures with details.

Combining multiple exposures we have obtained a mean spectrum for each nebula after the integration of the light along the slit. The line intensities were obtained using Gaussian line profile fitting procedures. In the cases of line blending, we have employed multiple Gaussian profile fitting in order to deconvolve the lines and measure the line intensities of each individual line. These measurements were carried out with the splot routine of the IRAF package. All the line intensities of a given spectrum were normalized to $\mathrm{H} \beta$. We estimated the error associated with the line flux intensities by $\sigma^{2}=\sigma_{\text {cont }}^{2}+\sigma_{\text {line }}^{2}$, where $\sigma_{\text {cont }}$ and $\sigma_{\text {line }}$ are the continuum rms and the Poisson error of the line respectively. All the observed line intensities were corrected for the effect of the interstellar extinction. This correction was done by comparing the observed $\mathrm{H} \gamma / \mathrm{H} \beta$ and $\mathrm{H} \alpha / \mathrm{H} \beta$ ratios with the theoretical ones by Hummer (1987) for an electron temperature of $10000 \mathrm{~K}$ and a density of $100 \mathrm{~cm}^{-3}$. The Galactic reddening function, $f(\lambda)$, of Savage \& Mathis (1979) was used. Table 1 lists Galactic reddening function, $f(\lambda)$, the emission line intensities corrected by reddening $I(\lambda)$, and the logarithmic extinction coefficient $c(\mathrm{H} \beta)$ for each object. We have measured the Balmer jump by linearly fitting the observed continua on both sides of the discontinuity (see more details in Paper I).

\subsection{Determination of electron density and temperature}

Electron temperature estimates $T_{\mathrm{e}}\left(\mathrm{O}\right.$ III) and $T_{\mathrm{e}}(\mathrm{N}$ II $)$ were derived from the $[\mathrm{O} \operatorname{III}](\lambda 4959+\lambda 5007) / \lambda 4363$ and $[\mathrm{N}$ II $](\lambda 6548+\lambda 6583) / \lambda 5755$ intensity ratios and electron densities $N_{\mathrm{e}}(\mathrm{S} \mathrm{II}), \quad N_{\mathrm{e}}(\mathrm{Cl} \mathrm{III}), \quad$ and $N_{\mathrm{e}}(\mathrm{Ar} I V)$ from the

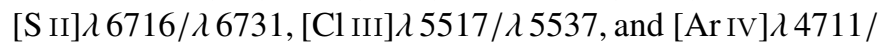
$\lambda 4740$ intensity ratios, respectively. These electron temperatures and densities were obtained by numerically solving the equilibrium equations for an $n$-level atom using the temden routine of the nebular package of the STSDAS/IRAF, using the same atomic parameters and electron density and temperature adopted in Paper I. We have also calculated the electron temperature from the ratio of the nebular Balmer discontinuity to $\mathrm{H} \beta,\left[F_{\lambda}(\lambda 3646-)-F_{\lambda}(\lambda 3646+)\right] / F(\mathrm{H} \beta)$ for NGC 1535 , NGC 2440, NGC 3242, and NGC 7009. In Paper I we have discussed in detail the possible sources of uncertainty in the determination of electron temperature and density.

\subsection{Determination of helium abundances}

We derived the $\mathrm{He}^{+} / \mathrm{H}^{+}$abundance from the emission lines $\lambda 4471, \lambda 5876$, and $\lambda 6678$ and then averaged these abundances weighting according to the intensity of the line. The $\mathrm{He}^{++} / \mathrm{H}^{+}$ratios were obtained from the He II $\lambda 4686$ line. The recombination coefficients used were from Storey \& Hummer (1995) for H and He II and from Benjamin et al. (1999) for He I, which includes the effects of collisional excitation from both $2^{3} \mathrm{~S}$ and $2^{1}$ metastable level. The elemental abundance of $\mathrm{He}$ was given by $\mathrm{He} / \mathrm{H}=\mathrm{He}^{+} / \mathrm{H}^{+}+\mathrm{He}^{++} / \mathrm{H}^{+}$.

\subsection{Determination of heavy abundances from collisional excited lines}

We have derived ionic abundances of $\mathrm{N}, \mathrm{O}, \mathrm{Ne}, \mathrm{S}$ and $\mathrm{Cl}$ from collisionally excited lines. These ionic abundances were derived by solving numerically the equilibrium equations for an $n$-level atom using the abund routine of the nebular package of the STSDAS/IRAF. The references used for the collision strengths $\mathrm{C}$, transition probabilities $\mathrm{A}$, and energy levels $\mathrm{E}$ are listed in Table 2.

The determination of ionic abundances derived from forbidden lines presents an exponential dependence on the assumed electron temperature. Therefore, appropriate temperatures must be adopted to calculate the abundance for a given ion. On the other hand, the dependence of ionic abundance estimates on the assumed electron density is insignificant. We have assumed the following scheme in the derivation of the ionic abundances: $T_{\mathrm{e}}(\mathrm{N}$ II $)$ and $N_{\mathrm{e}}\left(\mathrm{S}\right.$ II) were adopted for $\mathrm{N}^{+}, \mathrm{O}^{+}, \mathrm{S}^{+}$ and $\mathrm{S}^{2+}$, apart from the cases of NGC 1535 and NGC 3242, for which $T_{\mathrm{e}}(\mathrm{O}$ III $)$ was adopted instead, because $T_{\mathrm{e}}(\mathrm{N}$ II $)$ was not measured and NGC 1535, where $N_{\mathrm{e}}$ (ArIV) was the only density estimate; $T_{\mathrm{e}}(\mathrm{O}$ III) and a mean density obtained from $N_{\mathrm{e}}\left(\mathrm{Cl}\right.$ III) and $N_{\mathrm{e}}\left(\mathrm{Ar}\right.$ IV) were adopted for $\mathrm{Cl}^{++}, \mathrm{O}^{++}$ and $\mathrm{Ne}^{++}$; for $\mathrm{Ne}^{3+}$ and $\mathrm{Ne}^{4+}$ we used a mean density from $N_{\mathrm{e}}(\mathrm{Cl} \mathrm{III})$ and $N_{\mathrm{e}}(\mathrm{ArIV})$ and an electron temperature of $T_{\mathrm{e}}(\mathrm{O}$ III $)+2270 \mathrm{~K}$, which was indicated by Kingsburgh $\&$ Barlow (1994) based on the the results of photoionization models.

As discussed by Kingsburgh \& Barlow (1994), the fractions of neutral heavy element are assumed to be the same as neutral hydrogen and therefore the final abundances relative to hydrogen are not altered. So, the abundances of neutral species were not derived. The total abundance for a given element was a sum of the ionic abundances. We used the ionization correction factors icf discussed by Kingsburgh \& Barlow (1994) to correct for the unseen ions for a given element, except for $\mathrm{Cl}$, which was not discussed by those authors. For $\mathrm{Cl}$ we assumed the 
Table 2. References for the atomic data.

\begin{tabular}{llll}
\hline \hline Ion & $\mathrm{A}$ & $\mathrm{C}$ & $\mathrm{E}$ \\
\hline$[\mathrm{N} \mathrm{II}]$ & {$[3]$} & {$[9]$} & {$[1,2]$} \\
{$[\mathrm{O}$ II $]$} & {$[3]$} & {$[6,7]$} & {$[1,4,5]$} \\
{$[\mathrm{O}$ III $]$} & {$[3]$} & {$[9]$} & {$[1,8]$} \\
{$[\mathrm{Ne}$ III $]$} & {$[5,10]$} & {$[11]$} & {$[1]$} \\
{$[\mathrm{Ne}$ IV $]$} & {$[13,14]$} & {$[15]$} & {$[12]$} \\
{$[\mathrm{Ne} \mathrm{V}]$} & {$[5,24]$} & {$[9]$} & {$[1,10]$} \\
{$[\mathrm{S} \mathrm{II}]$} & {$[16,17]$} & {$[18]$} & {$[1,16]$} \\
{$[\mathrm{S} \mathrm{III}]$} & {$[5,19,20,21]$} & {$[22]$} & {$[1]$} \\
{$[\mathrm{Cl}$ III $]$} & {$[10,5]$} & {$[23]$} & {$[1]$} \\
\hline
\end{tabular}

References: [1] Bowen (1960); [2] Williams \& Livio (1995); [3] Wiese et al. (1996); [4] Fawcett (1975); [5] Kaufman \& Sugar (1986); [6] Pradhan (1976); [7] McLaughlin \& Bell (1993); [8] Moore (1985); [9] Lennon \& Burke (1994); [10] Mendoza (1983); [11] Butler \& Zeippen (1994); [12] Moore (1971); [13] Becker et al. (1989); [14] Bhatia \& Kastner (1988); [15] Giles (1981); [16] Verner et al. (1996); [17] Keenan et al. (1993); [18] Ramsbottom et al. (1996); [19] Mendoza \& Zeippen (1982); [20] Heise et al. (1995); [21] LaJohn \& Luke (1993); [22] Galavis et al. (1995); [23] Butler \& Zeippen (1989); [24] Bhatia \& Doschek (1993).

ionization correction factor adopted by Liu et al. (2000), based on the similarities of the ionization potentials of the $\mathrm{Cl}$ ion stages to those of the $\mathrm{S}$ ion stages. The errors in the ionic abundance were obtained by propagating the errors in electron temperature and line fluxes.

\subsection{Determination of $\mathrm{O}^{++}$abundance from recombination lines}

The $\mathrm{O}^{++}$abundance derived from observed recombination lines was obtained adopting the following equation:

$\frac{\mathrm{O}^{++}}{\mathrm{H}^{+}}=\frac{I(\mathrm{O} \mathrm{II}, \lambda)}{I(\mathrm{H} \beta)} \frac{\lambda(\mathrm{O} \mathrm{II})}{\lambda(\mathrm{H} \beta)} \frac{\alpha(\mathrm{H} \beta)}{\alpha(\mathrm{O} \mathrm{II}, \lambda)}$,

where $I(\mathrm{O} I \mathrm{I}, \lambda)$ is the dereddened flux of a given emission line $\lambda$ and $\alpha$ represents the recombination coefficient. The recombination coefficients depend only weakly on the adopted temperature and are essentially independent of the assumed density. For the calculation of $\mathrm{O}^{++}$abundances we adopted the [O III] electron temperatures. The effective recombination coefficients used were from Storey (1994) for 3s-3p transitions and from Liu et al. (1995) for 3d-4f transitions, assuming case A for doublets and case B for quartets. The errors of $\mathrm{O}^{++}$abundances were obtained by propagating the errors in the line fluxes.

We have derived $\mathrm{O}^{++}$abundances for NGC 3242 and NGC 7009, the only planetary nebulae in our sample with good signal-to-noise ratios in $\mathrm{O}$ II emission lines. We also obtained a spatial profile of the $\mathrm{O}^{++}$abundance for NGC 7009 from point-to-point measurements of the $\mathrm{O}$ II $\lambda 4661$ line. Although this O II $\lambda 4661$ line is blended with the [Fe III] + CIV $\lambda 4658$ line, it could be deconvolved and measured accurately. In Fig. 1 a sample of the spectral region around $4661 \AA$ for NGC 7009 is presented.

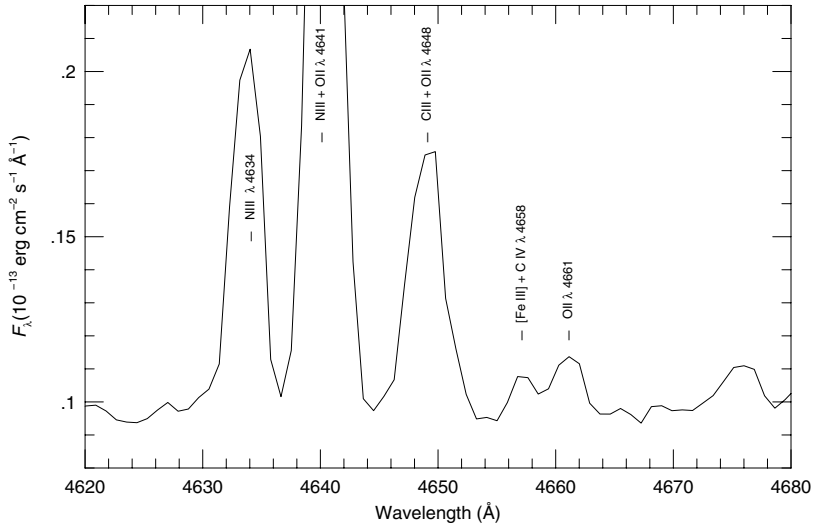

Fig. 1. A sample of the spectral region around $4661 \AA$ for NGC 7009.

\section{Results and discussions}

\subsection{Electron densities and temperatures}

Table 3 presents the temperatures and densities estimated from the integrated spectrum for each planetary nebula in our sample. We have compared these estimates with those obtained from point-to-point measurements along the nebular surface published in Paper I. In general the estimates of electron temperatures and densities obtained from the integrated spectrum and from point-to-point measurements are consistent with each other within the error estimates, although some differences are found in some objects. These two methods provide mean values of electron temperatures and densities with different weights, so different mean temperatures and densities can be obtained from these methods. We can find differences in the estimates obtained with the two methods mainly in objects that presents systematic variations of electron temperature and density along the nebular surface. In particular, we have found large differences in the determinations of [S II] and [Cl III] electron densities for NGC 6302. The [S II] and [Cl III] densities of NGC 6302 obtained from the integrated spectrum are about $4500 \mathrm{~cm}^{-3}$ and $25000 \mathrm{~cm}^{-3}$ lower than those derived from the point-to-point measurements. As this object shows an impressive spatial gradient of electron density, with the electron density peaking at the centre of the nebula and decreasing from the centre to the outer regions, we can expect higher densities derived from the point-to-point measurements (see Paper I).

\subsection{Ionic and total abundances}

Table 4 lists the He abundances derived from $\mathrm{He}$ I and He II recombination lines, the ionic and elemental abundances for heavy elements derived from forbidden lines, and the icf adopted. Table 5 presents a comparison between the elemental abundances derived in this paper and the ones previously published, expressed in units of $\log (\mathrm{X} / \mathrm{H})+12$, for $\mathrm{X}=\mathrm{He}, \mathrm{N}, \mathrm{O}$, $\mathrm{Ne}, \mathrm{S}$ and $\mathrm{Cl}$. We verified that our elemental abundances are in good agreement with those obtained by other authors. Also, our estimations support the classification of NGC 2440, NGC 3132, 
Table 3. Electron temperatures and densities.

\begin{tabular}{ccccccc}
\hline \hline Object & $N_{\mathrm{e}}\left(\mathrm{cm}^{-3}\right)$ & $N_{\mathrm{e}}\left(\mathrm{cm}^{-3}\right)$ & $N_{\mathrm{e}}\left(\mathrm{cm}^{-3}\right)$ & $T_{\mathrm{e}}(\mathrm{K})$ & $T_{\mathrm{e}}(\mathrm{K})$ & $T_{\mathrm{e}}(\mathrm{K})$ \\
& S II & Cl III & Ar IV & N II & O III & Bal \\
\hline NGC 1535 & & & $1672 \pm 101$ & & $11765 \pm 55$ & $8990 \pm 91$ \\
NGC 2438 & $143 \pm 71$ & & $2206 \pm 870$ & $11262 \pm 360$ & $11192 \pm 64$ & \\
NGC 2440 & $1807 \pm 83$ & $4898 \pm 2097$ & $2525 \pm 122$ & $11670 \pm 64$ & $14569 \pm 22$ & $12693 \pm 307$ \\
NGC 3132 & $637 \pm 52$ & $1289 \pm 706$ & $2265 \pm 856$ & $10454 \pm 78$ & $9390 \pm 112$ & \\
NGC 3242 & $1016 \pm 255$ & $2531 \pm 1227$ & $3665 \pm 141$ & & $12140 \pm 31$ & $9444 \pm 41$ \\
NGC 6302 & $2183 \pm 436$ & $13016 \pm 4640$ & $10630 \pm 137$ & $14381 \pm 310$ & $17927 \pm 61$ & \\
NGC 7009 & $3778 \pm 227$ & $5168 \pm 384$ & $5589 \pm 128$ & $10128 \pm 120$ & $9969 \pm 105$ & $8690 \pm 32$ \\
\hline
\end{tabular}

Table 4. Ionic and total abundances.

\begin{tabular}{|c|c|c|c|c|c|c|c|}
\hline & NGC 1535 & NGC 2438 & NGC 2440 & NGC 3132 & NGC 3242 & NGC 6302 & NGC 7009 \\
\hline $10^{2} \times \mathrm{He}^{+} / \mathrm{H}^{+}$ & $9.03 \pm 0.36$ & $8.63 \pm 0.20$ & $6.12 \pm 0.92$ & $11.99 \pm 0.72$ & $7.12 \pm 0.13$ & $8.64 \pm 0.37$ & $10.46 \pm 0.67$ \\
\hline $10^{2} \times \mathrm{He}^{++} / \mathrm{H}^{+}$ & $1.45 \pm 0.01$ & $2.69 \pm 0.01$ & $6.59 \pm 0.01$ & $0.57 \pm 0.02$ & $3.47 \pm 0.01$ & $6.51 \pm 0.05$ & $1.42 \pm 0.01$ \\
\hline $10^{2} \times \mathrm{He} / \mathrm{H}$ & $10.48 \pm 0.36$ & $11.32 \pm 0.20$ & $12.71 \pm 0.92$ & $12.56 \pm 0.72$ & $10.59 \pm 0.13$ & $15.15 \pm 0.37$ & $11.88 \pm 0.67$ \\
\hline $10^{5} \times \mathrm{N}^{+} / \mathrm{H}^{+}$ & $0.011 \pm 0.001$ & $3.13 \pm 0.07$ & $7.44 \pm 0.16$ & $9.56 \pm 0.24$ & $0.019 \pm 0.001$ & $5.86 \pm 0.44$ & $0.39 \pm 0.05$ \\
\hline$i c f(\mathrm{~N})$ & $117.7 \pm 19.7$ & $4.07 \pm 0.14$ & $8.26 \pm 0.77$ & $3.04 \pm 0.22$ & $220.7 \pm 17.0$ & $9.05 \pm 1.15$ & $45.05 \pm 9.80$ \\
\hline $10^{5} \times \mathrm{N} / \mathrm{H}$ & $1.29 \pm 0.25$ & $12.74 \pm 0.53$ & $61.45 \pm 5.89$ & $29.06 \pm 2.27$ & $4.19 \pm 0.39$ & $53.03 \pm 7.85$ & $17.57 \pm 4.44$ \\
\hline $10^{5} \times \mathrm{O}^{+} / \mathrm{H}^{+}$ & $0.22 \pm 0.028$ & $10.51 \pm 0.37$ & $3.73 \pm 0.12$ & $18.79 \pm 0.76$ & $0.14 \pm 0.01$ & $1.68 \pm 0.20$ & $1.01 \pm 0.21$ \\
\hline $10^{4} \times \mathrm{O}^{++} / \mathrm{H}^{+}$ & $2.32 \pm 0.24$ & $2.52 \pm 0.07$ & $1.52 \pm 0.03$ & $3.67 \pm 0.14$ & $2.36 \pm 0.06$ & $0.88 \pm 0.03$ & $4.08 \pm 0.14$ \\
\hline$i c f(\mathrm{O})$ & $1.10 \pm 0.04$ & $1.20 \pm 0.02$ & $1.63 \pm 0.14$ & $1.03 \pm 0.06$ & $1.30 \pm 0.01$ & $1.45 \pm 0.04$ & $1.09 \pm 0.06$ \\
\hline $10^{4} \times \mathrm{O} / \mathrm{H}$ & $2.59 \pm 0.28$ & $4.28 \pm 0.12$ & $3.08 \pm 0.27$ & $5.72 \pm 0.35$ & $3.09 \pm 0.09$ & $1.52 \pm 0.07$ & $4.55 \pm 0.29$ \\
\hline $10^{5} \times \mathrm{Ne}^{++} / \mathrm{H}^{+}$ & $6.43 \pm 0.44$ & $8.21 \pm 0.27$ & $3.21 \pm 0.07$ & $19.93 \pm 0.90$ & $4.93 \pm 0.14$ & $2.65 \pm 0.11$ & $12.13 \pm 0.50$ \\
\hline $10^{5} \times \mathrm{Ne}^{3+} / \mathrm{H}^{+}$ & & & $2.94 \pm 0.10$ & & $0.53 \pm 0.03$ & $1.74 \pm 0.10$ & $0.48 \pm 0.03$ \\
\hline $10^{5} \times \mathrm{Ne}^{4+} / \mathrm{H}^{+}$ & & $0.19 \pm 0.01$ & $4.11 \pm 0.08$ & & & $2.04 \pm 0.08$ & \\
\hline$i c f(\mathrm{Ne})$ & $1.12 \pm 0.17$ & 1.50 & 1.00 & $1.56 \pm 0.07$ & $1.31 \pm 0.05$ & 1.00 & $1.12 \pm 0.08$ \\
\hline $10^{5} \times \mathrm{Ne} / \mathrm{H}$ & $7.20 \pm 1.20$ & $12.60 \pm 0.27$ & $10.26 \pm 0.15$ & $31.09 \pm 1.98$ & $6.46 \pm 0.42$ & $6.43 \pm 0.17$ & $13.58 \pm 1.12$ \\
\hline $10^{8} \times \mathrm{Cl}^{++} / \mathrm{H}^{+}$ & & $7.24 \pm 0.18$ & $3.14 \pm 0.05$ & $17.64 \pm 0.60$ & $2.00 \pm 0.05$ & $2.84 \pm 0.09$ & $7.60 \pm 0.24$ \\
\hline$i c f(\mathrm{Cl})$ & & $1.50 \pm 0.10$ & $1.81 \pm 0.07$ & $1.48 \pm 0.09$ & $4.26 \pm 0.23$ & $1.98 \pm 0.14$ & $2.59 \pm 0.24$ \\
\hline $10^{7} \times \mathrm{Cl} / \mathrm{H}$ & & $1.09 \pm 0.07$ & $0.57 \pm 0.02$ & $2.61 \pm 0.19$ & $0.85 \pm 0.05$ & $0.56 \pm 0.04$ & $1.97 \pm 0.19$ \\
\hline $10^{7} \times \mathrm{S}^{+} / \mathrm{H}^{+}$ & & $7.94 \pm 0.16$ & $3.61 \pm 0.07$ & $23.71 \pm 0.58$ & $0.093 \pm 0.002$ & $5.15 \pm 0.35$ & $1.52 \pm 0.17$ \\
\hline $10^{6} \times \mathrm{S}^{++} / \mathrm{H}^{+}$ & $0.32 \pm 0.40$ & $3.26 \pm 0.16$ & $1.51 \pm 0.03$ & $7.69 \pm 0.37$ & $0.61 \pm 0.02$ & $1.60 \pm 0.07$ & $3.58 \pm 0.15$ \\
\hline$i c f(\mathrm{~S})$ & & $1.21 \pm 0.01$ & $1.46 \pm 0.04$ & $1.13 \pm 0.02$ & $4.20 \pm 0.11$ & $1.50 \pm 0.06$ & $2.49 \pm 0.18$ \\
\hline $10^{6} \times \mathrm{S} / \mathrm{H}$ & & $4.89 \pm 0.20$ & $2.73 \pm 0.09$ & $11.37 \pm 0.46$ & $2.60 \pm 0.11$ & $3.17 \pm 0.17$ & $9.28 \pm 0.75$ \\
\hline
\end{tabular}

and NGC 6302 as type I planetary nebulae (Peimbert 1978; Peimbert \& Torres-Peimbert 1983), which represents objects rich in helium and nitrogen.

The S/O abundance ratios derived for our sample of planetary nebulae are 0.11 to 0.92 dex lower than the values estimated for HII regions and the Sun (Esteban et al. 1998; Grevesse et al. 1996), with considerably larger discrepancies for NGC 2438, NGC 2440 and NGC 3242. These subsolar S/O ratios for the planetary nebulae also found by other authors (Aller \& Czyzak 1983; Aller \& Keyes 1987; de Freitas Pacheco et al. 1991; Kingsburgh \& Barlow 1994) were extensively discussed by Henry et al. (2004), who suggested that the problem lies in the $\mathrm{S}$ abundance estimates, which fail to adequately evaluate, through the use of $i c f \mathrm{~s}$, the amount of $\mathrm{S}^{+3}$ in the planetary nebulae. In particular, the standard ionization corrections might not be adequate if a nebula is matter-bounded, as is often the case for planetary nebulae.

The $\mathrm{O} / \mathrm{H}$ ratio for $\mathrm{NGC} 6302$ is 0.2 to $0.5 \mathrm{dex}$ lower than those obtained by other authors. Greater differences were found from Aller et al. (1981), who did not measure 
Table 5. Comparison of elemental abundances from different sources.

\begin{tabular}{|c|c|c|c|c|c|c|c|}
\hline Object & $\mathrm{He}$ & $\mathrm{N}$ & $\mathrm{O}$ & $\mathrm{Ne}$ & $S$ & $\mathrm{Cl}$ & Ref. \\
\hline \multirow[t]{3}{*}{ NGC 1535} & 11.02 & 7.11 & 8.41 & 7.86 & & & [1] \\
\hline & 10.96 & & 8.58 & 7.97 & & & [2] \\
\hline & 10.99 & 7.63 & 8.51 & 7.89 & & & [3] \\
\hline \multirow[t]{3}{*}{ NGC 2438} & 11.05 & 8.10 & 8.63 & 8.11 & 6.69 & 5.04 & [1] \\
\hline & 11.11 & 8.24 & 8.68 & & & & [5] \\
\hline & 11.15 & 8.00 & 8.38 & 7.60 & 6.51 & & [6] \\
\hline \multirow[t]{5}{*}{ NGC 2440} & 11.10 & 8.79 & 8.49 & 8.01 & 6.44 & 4.76 & {$[1]$} \\
\hline & 11.18 & 9.09 & 8.82 & 8.14 & & & [2] \\
\hline & 11.11 & 8.71 & 8.64 & 8.13 & 6.67 & & [6] \\
\hline & 11.08 & 8.98 & 8.64 & 7.95 & 6.30 & 5.11 & [7] \\
\hline & 11.09 & 8.26 & 8.39 & 8.04 & & & [8] \\
\hline \multirow[t]{3}{*}{ NGC 3132} & 11.10 & 8.46 & 8.77 & 8.49 & 7.06 & 5.42 & {$[1]$} \\
\hline & 11.11 & 8.68 & 8.98 & 8.56 & & & [2] \\
\hline & 11.08 & 8.37 & 8.82 & 8.49 & 7.02 & 5.36 & [8] \\
\hline \multirow[t]{5}{*}{ NGC 3242} & 11.02 & 7.62 & 8.49 & 7.81 & 6.41 & 4.93 & {$[1]$} \\
\hline & 11.03 & 7.71 & 8.72 & 8.03 & & & [2] \\
\hline & 11.00 & 7.53 & 8.52 & 7.89 & 6.38 & 4.94 & [8] \\
\hline & 10.96 & 7.96 & 8.64 & 8.04 & 6.51 & & [9] \\
\hline & 10.95 & 7.91 & 8.66 & 7.85 & 6.69 & 5.06 & [4] \\
\hline \multirow[t]{4}{*}{ NGC 6302} & 11.18 & 8.72 & 8.18 & 7.81 & 6.50 & 4.75 & [1] \\
\hline & 11.13 & 8.52 & 8.40 & 7.88 & 6.75 & 4.99 & [8] \\
\hline & 11.23 & 8.76 & 8.41 & & 6.69 & & [10] \\
\hline & 11.26 & 8.92 & 8.70 & 7.99 & 6.80 & 5.59 & [11] \\
\hline \multirow[t]{5}{*}{ NGC 7009} & 11.07 & 8.24 & 8.66 & 8.13 & 6.97 & 5.29 & {$[1]$} \\
\hline & 11.06 & 8.44 & 8.93 & 8.37 & & & [2] \\
\hline & 11.07 & 8.40 & 8.66 & 8.04 & 6.98 & & [6] \\
\hline & 11.04 & 8.23 & 8.67 & 8.04 & 6.92 & & [12] \\
\hline & 11.07 & 8.10 & 8.68 & 8.16 & 7.12 & & [13] \\
\hline Orion & 10.99 & 7.78 & 8.72 & 7.89 & 7.17 & 5.33 & [14] \\
\hline Sun & 10.99 & 7.97 & 8.87 & 8.08 & 7.33 & 5.50 & [15] \\
\hline
\end{tabular}

References: [1] this paper; [2] Torres-Peimbert \& Peimbert (1977); [3] Barker (1989); [4] Aller \& Czyzak (1983); [5] Guerrero \& Manchado (1999); [6] Kingsburgh \& Barlow (1994); [7] Hyung \& Aller (1998); [8] Tsamis et al. (2003); [9] Barker (1985); [10] de Freitas Pacheco et al. (1991); [11] Aller et al. (1981); [12] Gonçalves et al. (2003); [13] Barker (1983); [14] Esteban et al. (1998); [15] Grevesse et al. (1996).

the $[\mathrm{O}$ III $] \lambda \lambda 4959,5007$ lines. They calculated the chemical abundances with some measurements of emission line intensities combined with a simple theoretical model. For de Freitas Pacheco et al. (1991) and Tsamis et al. (2003), more modest differences of about 0.2 dex were found. In the
Table 6. $\mathrm{O}^{++} / \mathrm{H}^{+}$abundances derived from recombination lines.

\begin{tabular}{llll}
\hline \hline & & $\mathrm{NGC} 3242$ & $\mathrm{NGC} 7009$ \\
$\lambda(\AA)$ & Mult. & $\mathrm{O}^{++} / \mathrm{H}^{+} \times 10^{4}$ & $\mathrm{O}^{++} / \mathrm{H}^{+} \times 10^{3}$ \\
\hline 4662 & 1 & $5.91 \pm 0.84$ & $1.42 \pm 0.07$ \\
4676 & 1 & & $1.74 \pm 0.10$ \\
4317 & 2 & & $1.33 \pm 0.04$ \\
4415 & 5 & $5.01 \pm 1.25$ & $2.51 \pm 0.05$ \\
4132 & 19 & & $0.90 \pm 0.06$ \\
4155 & 19 & & $1.99 \pm 0.20$ \\
4089 & 48 & $5.27 \pm 1.51$ & $2.21 \pm 0.08$ \\
4304 & 54 & & $2.23 \pm 0.15$ \\
4276 & 67 & $6.10 \pm 2.71$ & $1.92 \pm 0.08$ \\
4284 & 67 & & $1.84 \pm 0.06$ \\
4609 & 92 & & $2.62 \pm 0.15$ \\
Average & & $5.57 \pm 0.20$ & $1.88 \pm 0.14$ \\
\hline
\end{tabular}

case of the estimates of de Freitas Pacheco et al. (1991) the [O III] $\lambda 4363$ line was not measured; $T_{\mathrm{e}}(\mathrm{O}$ III) was not adopted to calculate the $\mathrm{O}^{++} / \mathrm{H}^{+}$abundance. The values of the oxygen emission line intensities, mean electron temperatures and densities adopted by Tsamis et al. (2003) to calculate the $\mathrm{O}^{+} / \mathrm{H}^{+}$ and $\mathrm{O}^{++} / \mathrm{H}^{+}$and the ionic abundances are themselves very close to ours. However, they derived the $\mathrm{O}^{3+} / \mathrm{H}^{+}$abundance from the O IV] $\lambda 1401$ ultraviolet line. Thus, their ionization correction scheme was simpler and the atomic abundance obtained is probably more precise than ours, since they only needed to indirectly evaluate the presence of oxygen ions with higher stages of ionization. The lack of O IV] line measurements should be less noticeable in low ionization objects. The central star of NGC 6302 is the hottest of our sample with a temperature of about $250000 \mathrm{~K}$ (Casassus et al. 2000). This difference of about 0.2 dex in the $\mathrm{O} / \mathrm{H}$ ratio gives a general idea of the errors in the total abundance for planetary nebulae with very hot central stars introduced by the use of different $i c f$ s.

Table 6 lists the $\mathrm{O}^{++} / \mathrm{H}^{+}$abundance derived from recombination lines for NGC 3242 and NGC 7009. The values of the $\mathrm{O}^{++} / \mathrm{H}^{+}$abundance estimated from different $\mathrm{O}$ II emission lines are quite similar to one another, both for NGC 3242 and NGC 7009. However, these abundances are significantly higher than those obtained from collisionally excited lines, by a factor of about two for NGC 3242 and of four for NGC 7009. Similar results were found by Liu et al. (1995) for NGC 7009 and by Tsamis et al. (2003, 2004) for NGC 3242.

Figure 2 presents the spatial profiles in the emission lines [O III] $\lambda$ 4959, O II $\lambda$ 4661, and $\mathrm{H} \beta$ for NGC 7009 along the East-West direction. The emission of [O III] $\lambda 4959$ and O II $\lambda 4661$ lines are more concentrated in the central region of the nebula, while the emission of $\mathrm{H} \beta$ line is distributed in a larger area of the nebula.

Figure 3 shows the spatial profiles for NGC7009 of the $\mathrm{O}^{++} / \mathrm{H}^{+}$abundances derived from recombination and forbidden lines and of the ratio between these two abundance estimates. The $\mathrm{O}^{++} / \mathrm{H}^{+}$abundances derived from the OII $\lambda 4661$ recombination line are relatively constant 


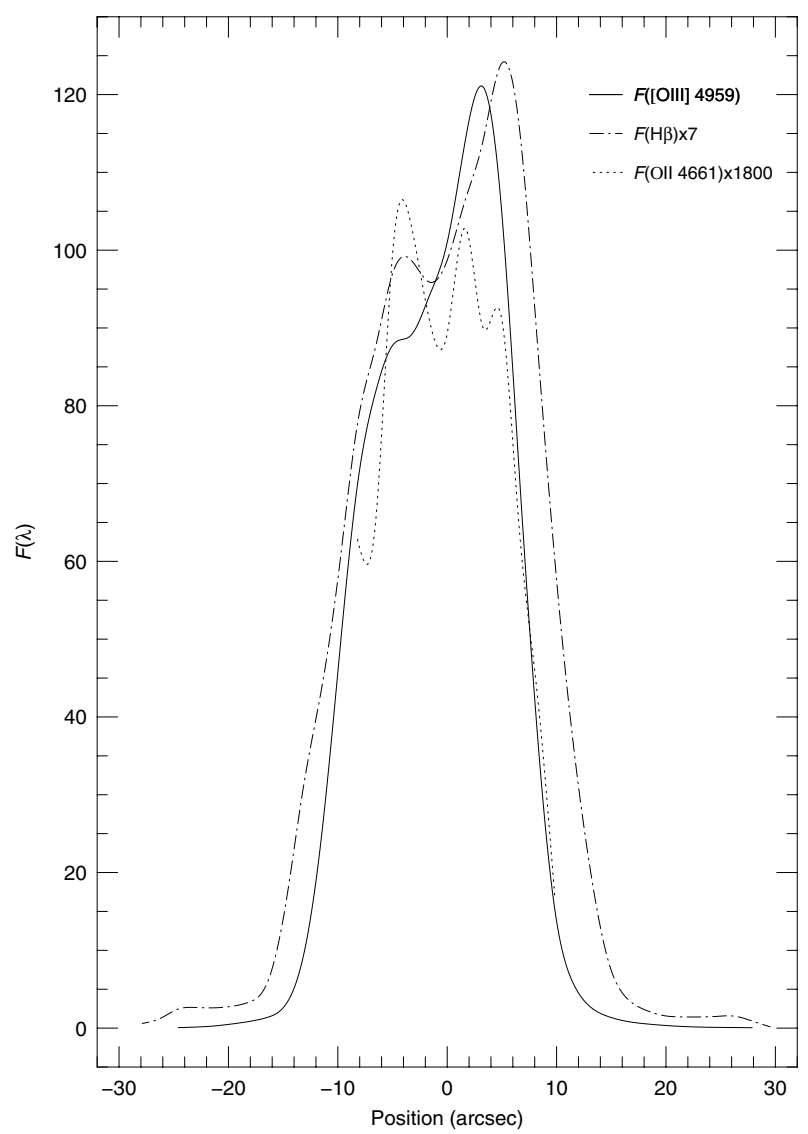

Fig. 2. Spatial profiles of the $\mathrm{H} \beta$, [O III] $\lambda 4959$ and $\mathrm{O}$ II $\lambda 4661$ fluxes (in units of $10^{-13} \mathrm{ergs} \mathrm{cm}^{-2} \mathrm{~s}^{-1}$ ) for NGC 7009 .

along the nebular surface, while those derived from the [O III $] \lambda \lambda 4959,5007$ forbidden lines exhibit a strong variation across the nebula. Consequently, the ratio between the $\mathrm{O}^{++} / \mathrm{H}^{+}$abundances derived from recombination lines and those from forbidden lines is not constant along the nebular surface, decreasing smoothly from the center to the edges of the nebula (see Fig. 3, lower panel), which suggests that the discrepancy between abundances from permitted and forbidden lines is at least in part caused by a large scale spatial variation of some physical proprieties of the nebula and not entirely explained by localized fluctuations of any property. Interestingly, the discrepancy between $\mathrm{O}^{++} / \mathrm{H}^{+}$abundance from permitted and forbidden lines is also not constant along the nebular surface of the planetary nebulae NGC 6720 (Garnett \& Dinerstein 2001) and NGC 6153 (Liu et al. 2000). For these nebulae, the differences in the $\mathrm{O}^{++} / \mathrm{H}^{+}$abundances are higher in the central part of the nebulae and lower in the outer regions of the nebulae.

We have looked for correlations between our $\mathrm{O}^{++}$abundance ratios and some physical properties of NGC 7009 to explain these discrepancies. We found a relationship between the argon electron density estimate $N_{\mathrm{e}}$ (Ar IV) and $\mathrm{O}^{++}$abundance ratio, with the abundance discrepancy increasing with the electron density (see Fig. 4).

One of the possible solutions to interpret the discrepancies between $\mathrm{O}^{++}$abundances estimated from recombination lines and forbidden lines is the presence of electron temperature

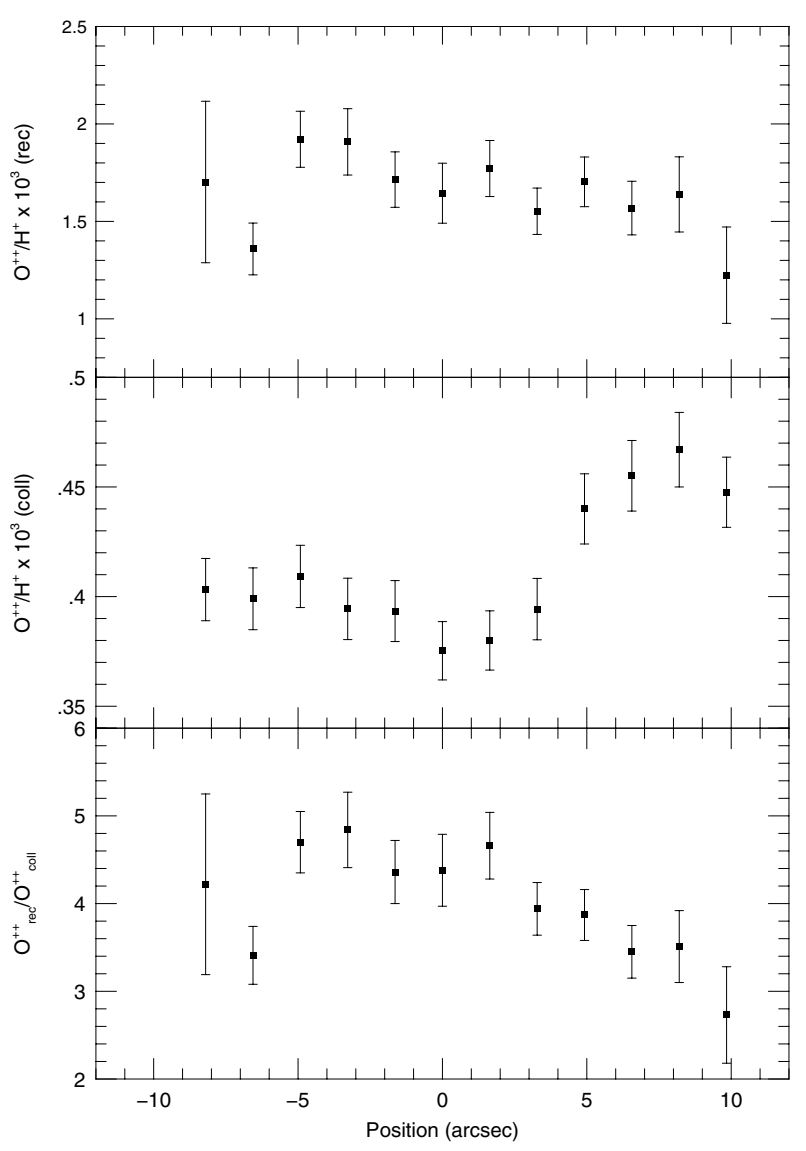

Fig. 3. Spatial profiles of the $\mathrm{O}^{++} / \mathrm{H}^{+}$abundances from the recombination line OІІ $\lambda 4661$ (rec) and from the forbidden lines [O III] $\lambda \lambda 4959,5007$ (coll) and of the ratio between these two abundance estimates for NGC 7009.

variations in ionized nebulae (Esteban et al. 1998, 1999; Peimbert et al. 1993; Ruiz et al. 2003; Peimbert et al. 2004). These temperature fluctuations were introduced by Peimbert (1967) and are usually characterized by the parameter $t^{2}$, the mean square temperature variation over the observed volume. If we assume that the ionic abundances derived from recombination lines are correct, we can estimate the $t^{2}$ value needed to obtain the same ionic abundances from forbidden lines, using the expressions given by Peimbert (1967) relating $T_{\mathrm{e}}(\mathrm{O}$ III $)$ to the $t^{2}$ and $T_{0}$. We can obtain compatible estimates of $\mathrm{O}^{++}$derived from recombination and forbidden lines assuming a value of $t^{2} \approx 0.09$ for both planetary nebulae NGC 3242 and NGC 7009.

Direct estimations of electron temperature fluctuations can be obtained through point-to-point measurements of the electron temperature across the nebula. In Paper I, we measured a temperature distribution with a variance relative to the mean corresponding to $t_{\mathrm{s}}^{2}(\mathrm{O}$ III $)=0.0015$ for NGC 3242 and $t_{\mathrm{s}}^{2}(\mathrm{O}$ III $)=0.0023$ for NGC 7009 from point-to-point measurements of [O III] electron temperature, which are much too low to have a significant impact on the determination of abundances derived from forbidden lines. However, as the temperature measured at any point is a mean value along the line of sight, $t_{\mathrm{s}}^{2}\left(\mathrm{O}\right.$ III) can only give a lower limit to $t^{2}$. From the difference between the [O III] and Balmer electron temperatures 


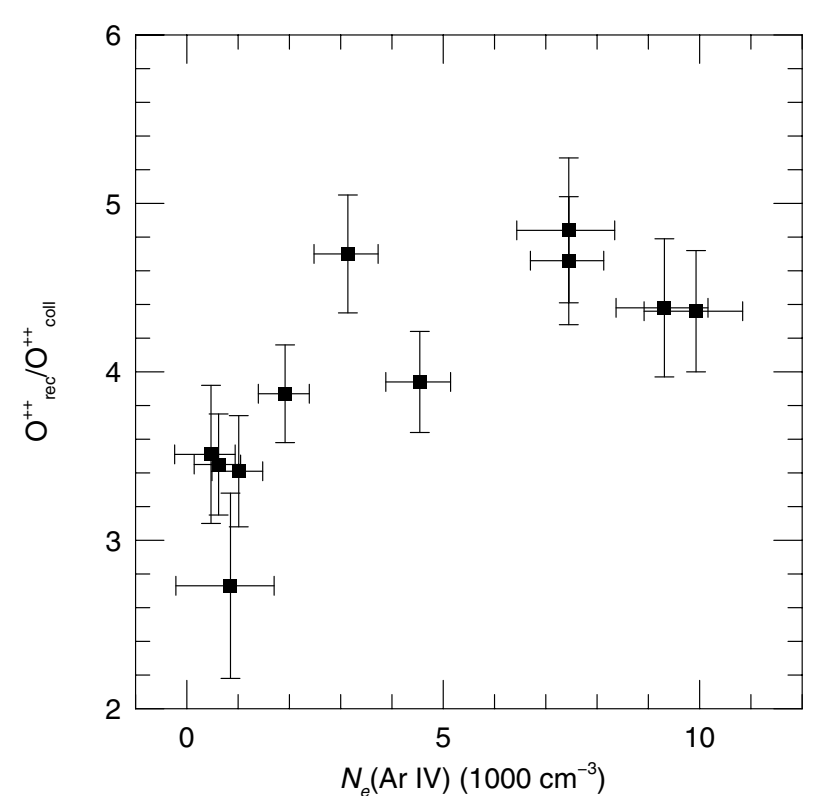

Fig. 4. Ratio between the values of $\mathrm{O}^{++} / \mathrm{H}^{+}$derived from recombination and forbidden lines versus electron density $N_{\mathrm{e}}(\mathrm{Ar} \mathrm{IV})$ for NGC 7009.

we have found $t^{2}=0.057$ for NGC 3242 and $t^{2}=0.027$ for NGC 7009, which are about two and three times lower than the value required to obtain the same abundances from recombination and forbidden lines, for NGC 3242 and NGC 7009, respectively. These differences between the [O III] and Balmer electron temperatures have been suggested as evidence in support of the presence of electron temperature fluctuations in gaseous nebulae to explain the discrepancies in abundances (Peimbert 1967; Liu \& Danziger 1993).

Other explanation that has been suggested is the presence of abundance inhomogeneities in the nebulae (Torres-Peimbert et al. 1990; Peimbert 1993; Liu et al. 2000). Liu et al. (2000) have produced models for NGC 6153 that consider the presence of hydrogen deficient clumps, which occupy a small fraction of the volume of the nebula. In these models the heavy element recombination lines are produced in a dense and cool region, while the forbidden lines are emitted in a hotter and less dense region. These models seem to reproduce well the intensities of the recombination and collisionally excited lines. However, according to Ruiz et al. (2003) and Peimbert et al. (2004), the similarities found between the widths and radial velocities of the $\mathrm{O}$ II and [O III] lines in the planetary nebulae NGC 5307 and NGC 5315, imply that these lines are produced in the same regions, in contradiction to the hypothesis of chemical inhomogeneities. Also, the models of Liu et al. (2000) fail to reproduce the low Balmer temperature observed.

Unfortunately, we did not find sufficient evidence from our data to explain the abundance discrepancies detected in NGC 7009 and NGC 3242. Detailed observational studies about spatial variations of abundances from recombination and forbidden lines in more objects could provide clues to solve this problem.

\section{Conclusions}

A study on the determination of the elemental abundances from collisional excited and permitted lines in the galactic planetary nebulae NGC 1535, NGC 2438, NGC 2440, NGC 3132, NGC 3242, NGC 6302, and NGC 7009 is presented. The data analyzed were obtained with long-slit spectrophotometry of high signal-to-noise ratio in the range of 3100 to $6900 \AA$.

We found that the $\mathrm{O}^{++} / \mathrm{H}^{+}$estimates derived from recombination lines are about a factor of four and two higher than those derived from forbidden lines for NGC 7009 and NGC 3242, respectively. The values of $\mathrm{O}^{++} / \mathrm{H}^{+}$abundance estimated from different $\mathrm{O}$ II emission lines are similar to one another, both for NGC 3242 and NGC 7009. The differences between $\mathrm{O}^{++} / \mathrm{H}^{+}$ratios derived from recombination lines and from forbidden lines decrease smoothly from the center to the edges in NGC 7009; this suggests that the discrepancies between the abundances from forbidden and permitted lines are at least in part caused by a large scale spatial variation of some physical proprieties of the nebula and not entirely explained by localized fluctuations of any single property. If we attribute these abundance differences to the presence of electron temperature fluctuations, a value of $t^{2} \approx 0.09$ is required. However, direct estimations of electron temperature fluctuations were obtained through point-to-point measurements of the electron temperature across the nebula, with a variance relative to the mean corresponding to $t_{\mathrm{s}}^{2}(\mathrm{O}$ III $)=0.0015$ for NGC 3242 and $t_{\mathrm{s}}^{2}(\mathrm{O}$ III $)=0.0023$ for NGC 7009 (Paper I), which are much low to have a significant impact on the determination of abundances derived from forbidden lines.

Acknowledgements. This work was partially supported by the Brazilian institutions CAPES, CNPQ, and LNA.

\section{References}

Aller, L. H., \& Czyzak, S. J. 1983, ApJS, 51, 211

Aller, L. H., \& Keyes, C. D. 1987, ApJS, 65, 405

Aller, L. H., Ross, J. E., Omara, B. J., \& Keyes, C. D. 1981, MNRAS, 197, 95

Barker, T. 1983, ApJ, 267, 630

Barker, T. 1985, ApJ, 294, 193

Barker, T. 1989, ApJ, 340, 921

Becker, S. R., Butler, K., \& Zeippen, C. J. 1989, A\&A, 221, 375

Benjamin, R. A., Skillman, E. D., \& Smits, D. P. 1999, ApJ, 514, 307

Bhatia, A. K., \& Kastner, S. O. 1988, ApJ, 332, 1063

Bhatia, A. K., \& Doschek, G. A. 1993, ADNDT, 55, 315

Bowen, I. S. 1960, ApJ, 132, 1

Butler, K., \& Zeippen, C. J. 1989, A\&A, 208, 337

Butler, K., \& Zeippen, C. J. 1994, A\&AS, 108, 1

Casassus, S., Roche, P. F., \& Barlow, M. J. 2000, MNRAS, 314, 657

de Freitas Pacheco, J. A., Maciel, W. J., Costa, R. D. D., \& Barbuy, B. 1991, A\&A, 250, 159

Esteban, C., Peimbert, M., Torres-Peimbert, S., \& Escalante, V. 1998, MNRAS, 295, 401

Esteban, C., Peimbert, M., Torres-Peimbert, S., García-Rojas, J., \& Rodríguez, M. 1999, ApJS, 120, 113

Fawcett, B. C. 1975, Atomic Data and Nuclear Data Tables, 16, 135

Galavis, M. E., Mendoza, C., \& Zeippen, C. J. 1995, A\&AS, 111, 347

Garnett, D. R., \& Dinerstein, H. L. 2001, ApJ, 558, 145

Giles, K. 1981, MNRAS, 195, 63P 
Gonçalves, D. R., Corradi, R. L. M., Mampaso, A., \& Perinotto, M. 2003, ApJ, 597, 975

Grevesse, N., Noels, A., \& Sauval, A. J. 1996, Cosmic Abundances, ASP Conf. Ser., 99, 117

Gruenwald, R., \& Viegas, S. M. 1995, A\&A, 303, 535

Guerrero, M. A., \& Manchado, A. 1999, ApJ, 522, 378

Heise, C., Smith, P. L., \& Calamai, A. G. 1995, ApJ, 451, L41

Henry, R. B. C., Kwitter, K. B., \& Balick, B. 2004, AJ, 127, 2284

Hummer, D. G., \& Storey, P. J. 1987, MNRAS, 224, 801

Hyung, S., \& Aller, L. H. 1998, PASP, 110, 466

Kaufman, V., \& Sugar, J. 1986, JPCRD, 15, 321

Keenan, F. P., Hibbert, A., Ojha, P. C., \& Conlon, E. S. 1993, Phys. Scr. A., 48, 129

Kingdon, J. B., \& Ferland, G. J. 1995, ApJ, 450, 691

Kingsburgh, R. L., \& Barlow, M. J. 1994, MNRAS, 271, 257

Krabbe, A. C., \& Copetti, M. V. F. 2002, A\&A, 387, 295

Krabbe, A. C., \& Copetti, M. V. F. 2005, A\&A, 443, 981

LaJohn, L., \& Luke, T., 1993, Phys. Scr. A., 47, 542

Lennon, D. J., \& Burke, V. M. 1994, A\&AS, 103, 273

Liu, X.-W. 1998, MNRAS, 295, 699

Liu, X.-W., \& Danziger, I. J. 1993, MNRAS, 263, 256

Liu, X.-W., Storey, P. J., Barlow, M. J., \& Clegg, R. E. S. 1995, MNRAS, 272, 369

Liu, X.-W., Storey, P. J., Danziger, I. J., Cohen, M., \& Bryce, M. 2000, MNRAS, 312, 585

McLaughlin, B. M., \& Bell, K. L. 1993, ApJ, 408, 753

Mendoza, C. 1983, Planetary Nebulae, IAU Symp., 103, 143

Mendoza, C., \& Zeippen, C. J. 1982, MNRAS, 199, 1025

Moore, C. E. 1971, Selected Tables of Atomic Spectra, NSRDS-NBS, 35,1

Moore, C. E. 1985, Selected Tables of Atomic Spectra, NSRDS-NBS 3 , Sect. 11
O’Dell, C. R., Peimbert, M., \& Peimbert, A. 2003, AJ, 125, 2590

Peimbert, M. 1967, ApJ, 150, 825

Peimbert, M. 1978, Planetary Nebulae, IAU Symp., 76, 215

Peimbert, M. 1993, Rev. Mex. Astron. Astrofis., 27, 9

Peimbert, M., \& Torres-Peimbert, S. 1983, Planetary Nebulae, IAU Symp., 103, 233

Peimbert, M., Storey, P. J., \& Torres-Peimbert, S. 1993, ApJ, 414, 626

Peimbert, M., Peimbert, A., Ruiz, M. T., \& Esteban, C. 2004, ApJS, 150,431

Pradhan, A. K. 1976, MNRAS, 177, 31

Ramsbottom, C. A., Bell, K. L., \& Stafford, R. P. 1996, ADNDT, 63, 57

Rubin, R. H., Bhatt, N. J., Dufour, R. J., et al. 2002, MNRAS, 334, 777

Rubin, R. H., Martin, P. G., Dufour, R. J., et al. 2003, MNRAS, 340, 362

Ruiz, M. T., Peimbert, A., Peimbert, M., \& Esteban, C. 2003, ApJ, 595,247

Savage, B. D., \& Mathis, J. S. 1979, ARA\&A, 17, 73

Storey, P. J. 1994, A\&A, 282, 999

Storey, P. J., \& Hummer, D. G. 1995, MNRAS, 272, 41

Torres-Peimbert, S., \& Peimbert, M. 1977, Rev. Mex. Astron. Astrofis., 2, 181

Torres-Peimbert, S., Peimbert, M., \& Pena, M. 1990, A\&A, 233, 540

Tsamis, Y. G., Barlow, M. J., Liu, X. -W., Danziger, I. J., \& Storey, P. J. 2003, MNRAS, 345

Tsamis, Y. G., Barlow, M. J., Liu, X.-W., Storey, P. J., \& Danziger, I. J. 2004, MNRAS, 353, 953

Verner D. A., Verner, E. M., \& Ferland, G. J. 1996, ADNDT, 64, 1

Wiese, W. L., Fuhr, J. R., \& Deters, T. M. 1996, JPCRD, Monograph 7

Williams, R. E., \& Livio, M. 1995, Proc. of STScI 8, 24 
A. C. Krabbe and M. V. F. Copetti: Chemical abundances, Online Material p 1

\section{Online Material}


A. C. Krabbe and M. V. F. Copetti: Chemical abundances, Online Material p 2

Table 1. Dereddened relative line fluxes $I(\lambda)$.

\begin{tabular}{|c|c|c|c|c|c|c|c|c|}
\hline Line & $f(\lambda)$ & $\begin{array}{c}\text { NGC } 1535 \\
I(\lambda)\end{array}$ & $\begin{array}{c}\text { NGC } 2438 \\
I(\lambda)\end{array}$ & $\begin{array}{c}\text { NGC 2440 } \\
I(\lambda)\end{array}$ & $\begin{array}{c}\text { NGC } 3132 \\
I(\lambda)\end{array}$ & $\begin{array}{c}\text { NGC } 3242 \\
I(\lambda)\end{array}$ & $\begin{array}{c}\text { NGC 6302 } \\
I(\lambda)\end{array}$ & $\begin{array}{c}\text { NGC 7009 } \\
I(\lambda)\end{array}$ \\
\hline$[\mathrm{Ne} \mathrm{V}] \lambda 3346$ & 0.389 & $\ldots$ & $\ldots$ & $97.21 \pm 0.40$ & $\ldots$ & $\ldots$ & $83.57 \pm 0.43$ & $\ldots$ \\
\hline $\mathrm{O}$ II $+[\mathrm{Cl}$ III $] \lambda 3354$ & 0.386 & $\ldots$ & $\ldots$ & $\ldots$ & $\ldots$ & $\ldots$ & $\ldots$ & $0.38 \pm 0.02$ \\
\hline O III $\lambda 3405$ & 0.364 & $\ldots$ & $\ldots$ & $\ldots$ & $0.22 \pm 0.01$ & $\ldots$ & $\ldots$ & $0.17 \pm 0.02$ \\
\hline O III + Ne II $\lambda 3415$ & 0.360 & $\ldots$ & $\ldots$ & $\ldots$ & $0.18 \pm 0.01$ & $\ldots$ & $\ldots$ & $0.32 \pm 0.02$ \\
\hline$[\mathrm{Ne} \mathrm{V}] \lambda 3426$ & 0.355 & $2.18 \pm 0.08$ & $5.93 \pm 0.39$ & $254.58 \pm 0.70$ & $\ldots$ & $1.73 \pm 0.02$ & $248.33 \pm 1.00$ & $\ldots$ \\
\hline O III $\lambda 3429$ & 0.354 & & $\ldots$ & & $\ldots$ & $1.15 \pm 0.02$ & & $1.69 \pm 0.03$ \\
\hline О Ііп $\lambda 3444$ & 0.349 & $11.57 \pm 0.12$ & $\ldots$ & $20.10+0.18$ & $\ldots$ & $9.68 \pm 0.02$ & $18.14 \pm 0.21$ & $9.52 \pm 0.04$ \\
\hline Не I $\lambda 3448$ & 0.348 & $\ldots$ & $\ldots$ & $20.10 \pm 0.18$ & $\ldots$ & $\ldots$ & $\ldots$ & $\ldots$ \\
\hline Не г $\lambda 3468$ & 0.342 & $\ldots$ & $\ldots$ & $\ldots$ & $\ldots$ & $\ldots$ & $0.82 \pm 0.20$ & $\ldots$ \\
\hline Не I $\lambda 3479$ & 0.339 & $\ldots$ & $\ldots$ & $\ldots$ & $\ldots$ & $\ldots$ & $\ldots$ & $0.12 \pm 0.03$ \\
\hline Не г $\lambda 3488$ & 0.336 & $\ldots$ & $\ldots$ & $\ldots$ & $\ldots$ & $\ldots$ & $\ldots$ & $0.08 \pm 0.03$ \\
\hline Не I $\lambda 3499$ & 0.334 & $\ldots$ & $\ldots$ & $\ldots$ & $\ldots$ & $0.05 \pm 0.02$ & $\ldots$ & $0.09 \pm 0.03$ \\
\hline Не г $\lambda 3512$ & 0.330 & $\ldots$ & $\ldots$ & $\ldots$ & $\ldots$ & $0.09 \pm 0.02$ & $\ldots$ & $0.16 \pm 0.03$ \\
\hline Не I $\lambda 3530$ & 0.325 & $\ldots$ & $\ldots$ & $\ldots$ & $\ldots$ & $0.14 \pm 0.02$ & $\ldots$ & $0.16 \pm 0.03$ \\
\hline Не г $\lambda 3554$ & 0.319 & $\ldots$ & $\ldots$ & $\ldots$ & $\ldots$ & $0.16 \pm 0.02$ & $0.55 \pm 0.20$ & $0.29 \pm 0.03$ \\
\hline Ne II $\lambda 3568$ & 0.315 & $\ldots$ & $\ldots$ & $\ldots$ & $\ldots$ & $\ldots$ & $\ldots$ & $0.15 \pm 0.03$ \\
\hline Не г $\lambda 3587$ & 0.310 & $0.48 \pm 0.07$ & $\ldots$ & $\ldots$ & $\ldots$ & $0.17 \pm 0.02$ & $0.99 \pm 0.21$ & $0.32 \pm 0.03$ \\
\hline Не I $\lambda 3614$ & 0.303 & $\ldots$ & $\ldots$ & $\ldots$ & $\ldots$ & $0.09 \pm 0.02$ & $\ldots$ & $0.22 \pm 0.03$ \\
\hline Не г $\lambda 3634$ & 0.298 & $0.91 \pm 0.07$ & $\ldots$ & $\ldots$ & $\ldots$ & $0.27 \pm 0.03$ & $0.71 \pm 0.22$ & $0.48 \pm 0.03$ \\
\hline Н г $\lambda 3687$ & 0.284 & $0.55 \pm 0.04$ & $\ldots$ & $\ldots$ & $0.50 \pm 0.12$ & $0.18 \pm 0.03$ & $0.16 \pm 0.22$ & $0.15 \pm 0.03$ \\
\hline Н г $\lambda 3692$ & 0.283 & $0.60 \pm 0.04$ & $\ldots$ & $0.70 \pm 0.14$ & $0.54 \pm 0.12$ & $0.28 \pm 0.03$ & $0.26 \pm 0.22$ & $0.33 \pm 0.03$ \\
\hline Н г $\lambda 3697$ & 0.282 & $0.79 \pm 0.04$ & $\ldots$ & $1.11 \pm 0.14$ & $0.84 \pm 0.13$ & $0.43 \pm 0.01$ & $0.43 \pm 0.22$ & $0.53 \pm 0.03$ \\
\hline H I + He I $\lambda 3704$ & 0.280 & $2.91 \pm 0.05$ & $\ldots$ & $2.00 \pm 0.02$ & $2.46 \pm 0.26$ & $1.46 \pm 0.01$ & $2.01 \pm 0.22$ & $1.82 \pm 0.01$ \\
\hline Н г $\lambda 3712$ & 0.278 & $2.55 \pm 0.05$ & $\ldots$ & $2.03 \pm 0.02$ & $1.76 \pm 0.19$ & $1.44 \pm 0.01$ & $1.33 \pm 0.13$ & $1.71 \pm 0.01$ \\
\hline [O II] $\lambda 3727$ & 0.275 & $9.37 \pm 0.08$ & $441.56 \pm 2.68$ & $147.33 \pm 0.32$ & $532.75 \pm 47.81$ & $6.00 \pm 0.02$ & $115.68 \pm 0.40$ & $20.98 \pm 0.04$ \\
\hline H13 $\lambda 3734$ & 0.273 & $2.90 \pm 0.05$ & $\ldots$ & $\ldots$ & $\ldots$ & $1.64 \pm 0.01$ & $\ldots$ & $1.94 \pm 0.01$ \\
\hline $\mathrm{H} 12 \lambda 3750$ & 0.269 & $3.54 \pm 0.05$ & $4.83 \pm 0.22$ & $3.78 \pm 0.03$ & $3.73 \pm 0.34$ & $2.58 \pm 0.01$ & $2.27 \pm 0.13$ & $2.90 \pm 0.01$ \\
\hline О Ііп $\lambda 3760$ & 0.267 & $2.19 \pm 0.05$ & $\ldots$ & $5.34 \pm 0.03$ & $0.54 \pm 0.11$ & $3.77 \pm 0.01$ & $4.08 \pm 0.13$ & $2.20 \pm 0.01$ \\
\hline H11 $\lambda 3770$ & 0.264 & $4.64 \pm 0.06$ & $5.76 \pm 0.22$ & $4.16 \pm 0.03$ & $5.23 \pm 0.45$ & $3.06 \pm 0.01$ & $3.24 \pm 0.13$ & $3.58 \pm 0.01$ \\
\hline H10 $\lambda 3798$ & 0.258 & $6.06 \pm 0.06$ & $6.62 \pm 0.23$ & $5.85 \pm 0.03$ & $6.94 \pm 0.58$ & $3.86 \pm 0.01$ & $4.53 \pm 0.13$ & $4.83 \pm 0.01$ \\
\hline He II $\lambda 3813$ & 0.254 & $\ldots$ & $\ldots$ & $0.39 \pm 0.01$ & $\ldots$ & $\ldots$ & $\ldots$ & $\ldots$ \\
\hline Не I $\lambda 3820$ & 0.253 & $1.41 \pm 0.04$ & $\ldots$ & $0.66 \pm 0.02$ & $2.31 \pm 0.21$ & $0.87 \pm 0.01$ & $1.24 \pm 0.02$ & $1.20 \pm 0.01$ \\
\hline H9 $\lambda 3835$ & 0.249 & $8.67 \pm 0.07$ & $9.91 \pm 0.23$ & $9.20 \pm 0.04$ & $9.88 \pm 0.78$ & $6.11 \pm 0.02$ & $6.97 \pm 0.04$ & $7.31 \pm 0.01$ \\
\hline [Ne III] $\lambda 3869$ & 0.242 & $115.84 \pm 0.22$ & $115.33 \pm 1.02$ & $106.46 \pm 0.21$ & $145.33 \pm 10.94$ & $88.84 \pm 0.06$ & $158.66 \pm 0.46$ & $109.75 \pm 0.12$ \\
\hline $\mathrm{He} \mathrm{I}+\mathrm{H} 8 \lambda 3889$ & 0.237 & $24.72 \pm 0.10$ & $22.91 \pm 0.34$ & $18.00 \pm 0.06$ & $29.99 \pm 2.21$ & $16.30 \pm 0.02$ & $21.58 \pm 0.07$ & $19.70 \pm 0.02$ \\
\hline He II $\lambda 3923$ & 0.230 & $\ldots$ & $\ldots$ & $0.66 \pm 0.01$ & $\ldots$ & $0.37 \pm 0.02$ & $0.63 \pm 0.02$ & $\ldots$ \\
\hline [Ne III] $\lambda 3967$ & 0.220 & $55.75 \pm 0.13$ & $28.27 \pm 0.31$ & $31.89 \pm 0.12$ & $55.66 \pm 3.71$ & $22.74 \pm 0.10$ & $62.90 \pm 0.18$ & $49.82 \pm 0.04$ \\
\hline H7 $\lambda 3970$ & 0.220 & $53.15 \pm 0.15$ & $12.79 \pm 0.22$ & $12.34 \pm 0.07$ & $53.00 \pm 3.11$ & $19.82 \pm 0.09$ & $02.90 \pm 0.18$ & $49.82 \pm 0.04$ \\
\hline Не г $\lambda 4009$ & 0.211 & $0.25 \pm 0.02$ & $\ldots$ & $\ldots$ & $\ldots$ & $0.21 \pm 0.02$ & $\ldots$ & $0.19 \pm 0.01$ \\
\hline Не I $\lambda 4026$ & 0.207 & $2.53 \pm 0.03$ & $2.75 \pm 0.20$ & $2.25 \pm 0.05$ & $3.07 \pm 0.20$ & $2.11 \pm 0.05$ & $3.38 \pm 0.04$ & $2.49 \pm 0.01$ \\
\hline [S II] + O II $\lambda 4069$ & 0.198 & $108+003$ & $4.00 \pm 0.20$ & $3.27 \pm 0.05$ & $6.95 \pm 0.41$ & $1.16 \pm 0.04$ & $11.66 \pm 0.05$ & $1.86 \pm 0.02$ \\
\hline [S II $]+$ O II $\lambda 4076$ & 0.196 & \pm 0.03 & $1.34 \pm 0.07$ & $0.89 \pm 0.04$ & $2.60 \pm 0.16$ & $0.35 \pm 0.02$ & $3.85 \pm 0.04$ & $0.88 \pm 0.02$ \\
\hline O II $\lambda 4084$ & 0.195 & $\cdots$ & $\ldots$ & $\ldots$ & $\ldots$ & $0.05 \pm 0.02$ & $\ldots$ & $\ldots$ \\
\hline O II $\lambda 4089$ & 0.194 & $\ldots$ & $\ldots$ & $\ldots$ & $\ldots$ & $0.07 \pm 0.02$ & $\ldots$ & $0.28 \pm 0.01$ \\
\hline N III + O II $\lambda 4097$ & 0.192 & $\ldots$ & $\ldots$ & $3.01 \pm 0.03$ & $\ldots$ & $1.74 \pm 0.05$ & $\ldots$ & $\ldots$ \\
\hline $\mathrm{H} \delta \lambda 4101$ & 0.191 & $29.92 \pm 0.08$ & $27.88 \pm 0.28$ & $29.30 \pm 0.05$ & $26.14 \pm 1.48$ & $27.04 \pm 0.07$ & $25.90 \pm 0.08$ & $25.93 \pm 0.07$ \\
\hline O II + He I $\lambda 4120$ & 0.187 & $0.26 \pm 0.02$ & $\ldots$ & $0.40 \pm 0.02$ & $0.54 \pm 0.06$ & $0.37 \pm 0.02$ & $0.61 \pm 0.04$ & $0.45 \pm 0.01$ \\
\hline O II $\lambda 4129$ & 0.185 & $\ldots$ & $\ldots$ & $\ldots$ & $\ldots$ & $0.10 \pm 0.02$ & $\ldots$ & $\ldots$ \\
\hline O Іі $\lambda 4133$ & 0.184 & $\ldots$ & $\ldots$ & $\ldots$ & $\ldots$ & $\ldots$ & $\ldots$ & $0.05 \pm 0.003$ \\
\hline Не I $\lambda 4144$ & 0.182 & $0.36 \pm 0.02$ & $\ldots$ & $0.34 \pm 0.02$ & $0.58 \pm 0.06$ & $0.31 \pm 0.02$ & $0.48 \pm 0.04$ & $0.40 \pm 0.01$ \\
\hline О Іі $\lambda 4155$ & 0.180 & $\ldots$ & $\ldots$ & $\ldots$ & $\ldots$ & $\ldots$ & $\ldots$ & $0.14 \pm 0.01$ \\
\hline [K v] $\lambda 4163$ & 0.178 & $\ldots$ & $\ldots$ & $0.24 \pm 0.02$ & $\ldots$ & $\ldots$ & $0.38 \pm 0.04$ & $\ldots$ \\
\hline Не I + O II $\lambda 4169$ & 0.177 & $\ldots$ & $\ldots$ & $\ldots$ & $0.19 \pm 0.04$ & $\ldots$ & $0.13 \pm 0.04$ & $0.08 \pm 0.01$ \\
\hline N II $\lambda 4176$ & 0.175 & $\ldots$ & $\ldots$ & $\ldots$ & $\ldots$ & $\ldots$ & $\ldots$ & $0.02 \pm 0.003$ \\
\hline N II $\lambda 4180$ & 0.174 & $\ldots$ & $\ldots$ & $0.05 \pm 0.01$ & $\ldots$ & $\ldots$ & $\ldots$ & $0.03 \pm 0.003$ \\
\hline O II + C III $\lambda 4186$ & 0.173 & $\ldots$ & $\ldots$ & $0.28 \pm 0.01$ & $\ldots$ & $0.33 \pm 0.02$ & $\ldots$ & $0.20 \pm 0.003$ \\
\hline He II $\lambda 4200$ & 0.170 & $0.41 \pm 0.02$ & $\ldots$ & $1.64 \pm 0.03$ & $0.20 \pm 0.04$ & $0.68 \pm 0.04$ & $1.46 \pm 0.05$ & $0.34 \pm 0.01$ \\
\hline Ne II $\lambda 4220$ & 0.166 & $\ldots$ & $\ldots$ & $\ldots$ & $\ldots$ & $\ldots$ & $\ldots$ & $0.08 \pm 0.003$ \\
\hline
\end{tabular}


Table 1. continued.

\begin{tabular}{|c|c|c|c|c|c|c|c|c|}
\hline Line & $f(\lambda)$ & $\begin{array}{c}\text { NGC } 1535 \\
I(\lambda)\end{array}$ & $\begin{array}{c}\text { NGC } 2438 \\
I(\lambda)\end{array}$ & $\begin{array}{c}\text { NGC 2440 } \\
I(\lambda) \\
\end{array}$ & $\begin{array}{c}\text { NGC } 3132 \\
I(\lambda)\end{array}$ & $\begin{array}{c}\text { NGC } 3242 \\
I(\lambda)\end{array}$ & $\begin{array}{c}\text { NGC 6302 } \\
I(\lambda)\end{array}$ & $\begin{array}{c}\text { NGC 7009 } \\
I(\lambda)\end{array}$ \\
\hline $\mathrm{N}_{\text {II }}+\mathrm{Fe}$ V $\lambda 4228$ & 0.165 & $0.37 \pm 0.02$ & $\ldots$ & $0.56 \pm 0.02$ & $\ldots$ & $0.15 \pm 0.01$ & $0.41 \pm 0.05$ & $0.25 \pm 0.01$ \\
\hline N II $\lambda 4237$ & 0.163 & $\ldots$ & $\ldots$ & $\ldots$ & $\ldots$ & $\ldots$ & $\ldots$ & $0.10 \pm 0.003$ \\
\hline N II $\lambda 4242$ & 0.162 & $\ldots$ & $\ldots$ & $\ldots$ & $\ldots$ & $\ldots$ & $\ldots$ & $0.05 \pm 0.003$ \\
\hline O II $\lambda 4254$ & 0.160 & $\ldots$ & $\ldots$ & $\ldots$ & $\ldots$ & $\ldots$ & $\ldots$ & $0.05 \pm 0.003$ \\
\hline C II $\lambda 4267$ & 0.157 & $0.36 \pm 0.02$ & $1.26 \pm 0.07$ & $0.43 \pm 0.02$ & $0.82 \pm 0.06$ & $0.77 \pm 0.04$ & $0.16 \pm 0.05$ & $0.87 \pm 0.01$ \\
\hline О Іі $\lambda 4276$ & 0.155 & $\ldots$ & $\ldots$ & $\ldots$ & $\ldots$ & $0.09 \pm 0.04$ & $\ldots$ & $0.27 \pm 0.01$ \\
\hline О Іі $\lambda 4284$ & 0.154 & $\ldots$ & $\ldots$ & $\ldots$ & $\ldots$ & $\ldots$ & $\ldots$ & $0.10 \pm 0.003$ \\
\hline O II $\lambda 4304$ & 0.150 & $\ldots$ & $\ldots$ & $\ldots$ & $\ldots$ & $\ldots$ & $\ldots$ & $0.13 \pm 0.01$ \\
\hline О ІІ $\lambda 4317$ & 0.147 & $\ldots$ & $\ldots$ & $\ldots$ & $\ldots$ & $\ldots$ & $\ldots$ & $0.23 \pm 0.01$ \\
\hline $\mathrm{H} \gamma \lambda 4340$ & 0.143 & $46.80 \pm 0.08$ & $46.80 \pm 0.29$ & $46.80 \pm 0.12$ & $46.80 \pm 1.98$ & $46.80 \pm 0.08$ & $46.80 \pm 0.13$ & $46.80 \pm 0.08$ \\
\hline [O III] $\lambda 4363$ & 0.138 & $12.65 \pm 0.04$ & $9.56 \pm 0.15$ & $23.98 \pm 0.07$ & $4.56 \pm 0.19$ & $14.05 \pm 0.04$ & $36.46 \pm 0.10$ & $7.57 \pm 0.02$ \\
\hline Ne II + N III $\lambda 4379$ & 0.135 & $0.16 \pm 0.01$ & $\ldots$ & $0.44 \pm 0.02$ & $\ldots$ & $0.23 \pm 0.01$ & $0.17 \pm 0.05$ & $0.45 \pm 0.01$ \\
\hline He II $\lambda 4388$ & 0.134 & $0.58 \pm 0.01$ & $\ldots$ & $0.32 \pm 0.01$ & $0.75 \pm 0.04$ & $0.40 \pm 0.01$ & $0.62 \pm 0.05$ & $0.57 \pm 0.01$ \\
\hline Ne in $\lambda 4409$ & 0.129 & $\ldots$ & $\ldots$ & $\ldots$ & $\ldots$ & $\ldots$ & $\ldots$ & $0.04 \pm 0.004$ \\
\hline O пі $\lambda 4415$ & 0.127 & $\ldots$ & $\ldots$ & $\ldots$ & $\ldots$ & $0.04 \pm 0.01$ & $\ldots$ & $0.20 \pm 0.004$ \\
\hline Не г $\lambda 4471$ & 0.110 & $4.06 \pm 0.02$ & $4.46 \pm 0.13$ & $2.86 \pm 0.02$ & $5.74 \pm 0.20$ & $3.52 \pm 0.03$ & $5.90 \pm 0.05$ & $5.00 \pm 0.02$ \\
\hline $\mathrm{C}_{\text {II }}+\mathrm{O}_{\text {II }} \lambda 4491$ & 0.104 & $\ldots$ & $\ldots$ & $\ldots$ & $\ldots$ & $\ldots$ & $\ldots$ & $0.09 \pm 0.004$ \\
\hline N III $\lambda 4511$ & 0.098 & $\ldots$ & $\ldots$ & $0.34 \pm 0.01$ & $\ldots$ & $0.11 \pm 0.03$ & $\ldots$ & $0.17 \pm 0.01$ \\
\hline N III $\lambda 4518$ & 0.096 & $\ldots$ & $\ldots$ & $\ldots$ & $\ldots$ & $\ldots$ & $\ldots$ & $0.14 \pm 0.01$ \\
\hline N III $\lambda 4524$ & 0.094 & $\ldots$ & $\ldots$ & $\ldots$ & $\ldots$ & $\ldots$ & $\ldots$ & $0.05 \pm 0.01$ \\
\hline N II + N III $\lambda 4530$ & 0.092 & $\ldots$ & $\ldots$ & $\ldots$ & $\ldots$ & $\ldots$ & $\ldots$ & $0.06 \pm 0.01$ \\
\hline N III $\lambda 4535$ & 0.091 & $\ldots$ & $\ldots$ & $\ldots$ & $\ldots$ & $\ldots$ & $\ldots$ & $0.07 \pm 0.01$ \\
\hline Не II $\lambda 4541$ & 0.089 & $0.66 \pm 0.01$ & $1.67 \pm 0.07$ & $2.75 \pm 0.02$ & $0.37 \pm 0.02$ & $1.22 \pm 0.03$ & $2.53 \pm 0.02$ & $0.55 \pm 0.01$ \\
\hline N II $\lambda 4552$ & 0.085 & $\ldots$ & $\ldots$ & $\ldots$ & $\ldots$ & $\ldots$ & $\ldots$ & $0.24 \pm 0.01$ \\
\hline $\left.\mathrm{Mg}_{\mathrm{I}}\right] \lambda 4562$ & 0.083 & $\ldots$ & $1.00 \pm 0.06$ & $0.14 \pm 0.01$ & $0.38 \pm 0.02$ & $\ldots$ & $\ldots$ & $0.07 \pm 0.01$ \\
\hline $\left.\mathrm{Mg}_{\mathrm{I}}\right] \lambda 4571$ & 0.080 & $\ldots$ & $0.60 \pm 0.05$ & $0.21 \pm 0.01$ & $0.36 \pm 0.02$ & $\ldots$ & $0.22 \pm 0.01$ & $0.09 \pm 0.01$ \\
\hline О Іі $\lambda 4591$ & 0.074 & $\ldots$ & $\ldots$ & $\ldots$ & $\ldots$ & $\ldots$ & $\ldots$ & $0.08 \pm 0.01$ \\
\hline О пі $\lambda 4596$ & 0.073 & $\ldots$ & $\ldots$ & $\ldots$ & $\ldots$ & $\ldots$ & $\ldots$ & $0.05 \pm 0.01$ \\
\hline N II $\lambda 4601$ & 0.071 & $\ldots$ & $\ldots$ & $\ldots$ & $\ldots$ & $\ldots$ & $\ldots$ & $0.04 \pm 0.01$ \\
\hline $\mathrm{Nv}+\mathrm{O}_{\text {II }} \lambda 4604$ & 0.070 & $\ldots$ & $\ldots$ & $0.10 \pm 0.01$ & $\ldots$ & $\ldots$ & $\ldots$ & $\ldots$ \\
\hline$[\mathrm{Fe} I I I]+\mathrm{N}_{\mathrm{I}}$ & 0.070 & $\ldots$ & $\ldots$ & $0.47 \pm 0.01$ & $\ldots$ & $\ldots$ & $0.57 \pm 0.01$ & $\ldots$ \\
\hline O пі $\lambda 4609$ & 0.069 & $\ldots$ & $\ldots$ & $\ldots$ & $\ldots$ & $\ldots$ & $\ldots$ & $0.16 \pm 0.01$ \\
\hline N III $\lambda 4634$ & 0.062 & $0.43 \pm 0.01$ & $\ldots$ & $1.89 \pm 0.02$ & $0.21 \pm 0.02$ & $1.01 \pm 0.03$ & $2.63 \pm 0.02$ & $1.19 \pm 0.01$ \\
\hline $\mathrm{N}$ III + O II $\lambda 4641$ & 0.060 & $1.08 \pm 0.01$ & $\ldots$ & $4.12 \pm 0.02$ & $0.83 \pm 0.03$ & $2.60 \pm 0.03$ & $5.68 \pm 0.06$ & $3.28 \pm 0.02$ \\
\hline С піг $\lambda 4647$ & 0.058 & +0.01 & $\ldots$ & $0.18 \pm 0.01$ & $\ldots$ & $0.22 \pm 0.04$ & $\ldots$ & $0.97+0.01$ \\
\hline O II + C III $\lambda 4650$ & 0.057 & $0.65 \pm 0.01$ & $\ldots$ & $0.32 \pm 0.01$ & $0.36 \pm 0.02$ & $0.70 \pm 0.02$ & $\ldots$ & $0.91 \pm 0.01$ \\
\hline$[\mathrm{Fe}$ III $]+\mathrm{C}_{\text {IV }} \lambda 4658$ & 0.055 & $\ldots$ & $\ldots$ & $1.02 \pm 0.02$ & $\ldots$ & $0.20 \pm 0.01$ & $0.50 \pm 0.01$ & $0.12 \pm 0.01$ \\
\hline O пі $\lambda 4662$ & 0.054 & $\ldots$ & $\ldots$ & $\ldots$ & $\ldots$ & $0.07 \pm 0.01$ & $\ldots$ & $0.18 \pm 0.01$ \\
\hline O Іі $\lambda 4676$ & 0.050 & $\ldots$ & $\ldots$ & $\ldots$ & $\ldots$ & $\ldots$ & $\ldots$ & $0.17 \pm 0.01$ \\
\hline He II $\lambda 4686$ & 0.047 & $16.98 \pm 0.04$ & $31.72 \pm 0.16$ & $74.86 \pm 0.11$ & $7.07 \pm 0.21$ & $40.53 \pm 0.05$ & $71.40 \pm 0.54$ & $17.06 \pm 0.06$ \\
\hline [Ar IV] + He I $\lambda 4712$ & 0.040 & $4.53 \pm 0.02$ & $1.91 \pm 0.07$ & $11.08 \pm 0.04$ & $1.29 \pm 0.04$ & $5.95 \pm 0.02$ & $14.97 \pm 0.04$ & $4.54 \pm 0.02$ \\
\hline$[\mathrm{Ne}$ IV] $\lambda 4725$ & 0.036 & $\ldots$ & $\ldots$ & $1.79 \pm 0.02$ & $\ldots$ & $0.12 \pm 0.01$ & $3.23 \pm 0.03$ & $0.04 \pm 0.01$ \\
\hline [Ar IV] $\lambda 4740$ & 0.032 & $3.36 \pm 0.02$ & $1.25 \pm 0.06$ & $9.32 \pm 0.03$ & $0.62 \pm 0.02$ & $5.29 \pm 0.02$ & $18.31 \pm 0.07$ & $4.39 \pm 0.02$ \\
\hline C II + N II $\lambda 4802$ & 0.016 & $\ldots$ & $\ldots$ & $0.09 \pm 0.01$ & $\ldots$ & $\ldots$ & $\ldots$ & $\ldots$ \\
\hline $\mathrm{H} \beta \lambda 4861$ & 0.000 & $100.00 \pm 0.10$ & $100.00 \pm 0.30$ & $100.00 \pm 0.13$ & $100.00 \pm 2.95$ & $100.00 \pm 0.10$ & $100.00 \pm 0.18$ & $100.00 \pm 0.19$ \\
\hline$[\mathrm{Fe}$ III $] \lambda 4881$ & -0.005 & $\ldots$ & $\ldots$ & $0.19 \pm 0.02$ & $\ldots$ & $\ldots$ & $\ldots$ & $\ldots$ \\
\hline Не г $\lambda 4922$ & -0.016 & $1.11 \pm 0.01$ & $0.84 \pm 0.09$ & $0.73 \pm 0.02$ & $1.44 \pm 0.04$ & $0.90 \pm 0.02$ & $1.43 \pm 0.03$ & $1.49 \pm 0.02$ \\
\hline [O III] $\lambda 4932$ & -0.018 & $0.13 \pm 0.01$ & $\ldots$ & $0.30 \pm 0.02$ & $\ldots$ & $0.26 \pm 0.02$ & $0.28 \pm 0.03$ & $0.13 \pm 0.01$ \\
\hline O Іі $\lambda 4943$ & -0.021 & $\ldots$ & $\ldots$ & $\ldots$ & $\ldots$ & $\ldots$ & $0.46 \pm 0.03$ & $\ldots$ \\
\hline Nv $\lambda 4945$ & -0.021 & $\ldots$ & $\ldots$ & $0.22 \pm 0.02$ & $\ldots$ & $\ldots$ & $\ldots$ & $\ldots$ \\
\hline [O III] $\lambda 4959$ & -0.025 & $405.88 \pm 0.94$ & $358.18 \pm 0.90$ & $450.38 \pm 0.10$ & $287.46 \pm 1.06$ & $416.43 \pm 0.36$ & $424.98 \pm 2.81$ & $390.25 \pm 0.59$ \\
\hline [O III] $\lambda 5007$ & -0.037 & $1189.38 \pm 2.56$ & $1045.42 \pm 2.57$ & $1312.31 \pm 3.01$ & $885.72 \pm 3.17$ & $1204.84 \pm 1.02$ & $1271.16 \pm 9.04$ & $1170.75 \pm 1.77$ \\
\hline Не г $\lambda 5015$ & -0.039 & $\ldots$ & $0.92 \pm 0.10$ & $\ldots$ & $\ldots$ & $\ldots$ & $\ldots$ & $\ldots$ \\
\hline$\left[\mathrm{N}_{\mathrm{I}}\right] \lambda 5200$ & -0.082 & $\ldots$ & $\ldots$ & $8.71 \pm 0.07$ & $9.73 \pm 0.15$ & $\ldots$ & $19.49 \pm 0.39$ & $\ldots$ \\
\hline He II $\lambda 5412$ & -0.128 & $1.27 \pm 0.04$ & $3.19 \pm 0.24$ & $7.03 \pm 0.07$ & $\ldots$ & $3.02 \pm 0.02$ & $5.02 \pm 0.31$ & $1.24 \pm 0.01$ \\
\hline [Cl III] $\lambda 5517$ & -0.149 & $\ldots$ & $0.98 \pm 0.24$ & $0.55 \pm 0.06$ & $1.23 \pm 0.07$ & $0.26 \pm 0.02$ & $0.54 \pm 0.06$ & $0.48 \pm 0.01$ \\
\hline$\left[\mathrm{Cl}_{\text {III }}\right] \lambda 5537$ & -0.153 & $\ldots$ & $0.54 \pm 0.24$ & $0.66 \pm 0.06$ & $1.06 \pm 0.07$ & $0.25 \pm 0.02$ & $0.88 \pm 0.06$ & $0.59 \pm 0.01$ \\
\hline $\mathrm{N}_{\text {II }} \lambda 5667$ & -0.176 & $\ldots$ & $\ldots$ & $\ldots$ & $\ldots$ & $\ldots$ & $\ldots$ & $0.05 \pm 0.01$ \\
\hline
\end{tabular}


A. C. Krabbe and M. V. F. Copetti: Chemical abundances, Online Material p 4

Table 1. continued.

\begin{tabular}{|c|c|c|c|c|c|c|c|c|}
\hline Line & $f(\lambda)$ & $\begin{array}{c}\text { NGC } 1535 \\
I(\lambda)\end{array}$ & $\begin{array}{c}\text { NGC } 2438 \\
I(\lambda)\end{array}$ & $\begin{array}{c}\text { NGC } 2440 \\
I(\lambda)\end{array}$ & $\begin{array}{c}\text { NGC } 3132 \\
I(\lambda)\end{array}$ & $\begin{array}{c}\text { NGC } 3242 \\
I(\lambda)\end{array}$ & $\begin{array}{c}\text { NGC } 6302 \\
I(\lambda)\end{array}$ & $\begin{array}{c}\text { NGC } 7009 \\
I(\lambda)\end{array}$ \\
\hline N II $\lambda 5669$ & -0.176 & $\ldots$ & $\ldots$ & $\ldots$ & $\ldots$ & $\ldots$ & $\ldots$ & $0.16 \pm 0.01$ \\
\hline [N II] $\lambda 5755$ & -0.191 & $\ldots$ & $3.79 \pm 0.25$ & $11.70 \pm 0.09$ & $8.22 \pm 0.10$ & $\ldots$ & $19.80 \pm 0.46$ & $0.46 \pm 0.01$ \\
\hline C IV $\lambda 5802$ & -0.198 & $\ldots$ & $\ldots$ & $\ldots$ & $\ldots$ & $0.35 \pm 0.02$ & ... & ... \\
\hline C IV $\lambda 5812$ & -0.200 & $\ldots$ & $\ldots$ & $\ldots$ & $\ldots$ & $0.20 \pm 0.02$ & $\ldots$ & $\ldots$ \\
\hline Не г $\lambda 5876$ & -0.210 & $12.63 \pm 0.04$ & $11.56 \pm 0.34$ & $8.24 \pm 0.08$ & $17.25 \pm 0.17$ & $10.26 \pm 0.03$ & $19.08 \pm 0.48$ & $15.70 \pm 0.04$ \\
\hline Не II $\lambda 6037$ & -0.235 & $\ldots$ & $\ldots$ & $\ldots$ & $\ldots$ & $\ldots$ & $\ldots$ & $0.45 \pm 0.03$ \\
\hline K IV $\lambda 6102$ & -0.245 & $\ldots$ & $\ldots$ & $\ldots$ & $\ldots$ & $0.28 \pm 0.03$ & $\ldots$ & $\ldots$ \\
\hline He II $\lambda 6171$ & -0.255 & $\ldots$ & $\ldots$ & $\ldots$ & $\ldots$ & $0.14 \pm 0.03$ & $\ldots$ & $\ldots$ \\
\hline Не II $\lambda 6234$ & -0.264 & $\ldots$ & $\ldots$ & $0.32 \pm 0.04$ & $\ldots$ & $0.13 \pm 0.03$ & $\ldots$ & $\ldots$ \\
\hline [O I] $\lambda 6300$ & -0.274 & $0.10 \pm 0.03$ & $31.77 \pm 0.88$ & $14.26 \pm 0.11$ & $33.55 \pm 0.37$ & $0.12 \pm 0.03$ & $24.39 \pm 0.75$ & $0.71 \pm 0.03$ \\
\hline [S III] $\lambda 6312$ & -0.275 & $0.28 \pm 0.03$ & $2.18 \pm 0.20$ & $2.51 \pm 0.04$ & $2.58 \pm 0.06$ & $0.53 \pm 0.03$ & $5.09 \pm 0.20$ & $1.54 \pm 0.03$ \\
\hline [O I] $\lambda 6364$ & -0.282 & $0.24 \pm 0.03$ & $9.86 \pm 0.34$ & $4.87 \pm 0.05$ & $11.61 \pm 0.14$ & $0.13 \pm 0.03$ & $7.95 \pm 0.28$ & $\ldots$ \\
\hline [S III] $\lambda 6312$ & -0.275 & $0.28 \pm 0.03$ & $2.18 \pm 0.20$ & $2.51 \pm 0.04$ & $2.58 \pm 0.06$ & $0.53 \pm 0.03$ & $5.09 \pm 0.20$ & $1.54 \pm 0.03$ \\
\hline [O I] $\lambda 6364$ & -0.282 & $0.24 \pm 0.03$ & $9.86 \pm 0.34$ & $4.87 \pm 0.05$ & $11.61 \pm 0.14$ & $0.13 \pm 0.03$ & $7.95 \pm 0.28$ & $\ldots$ \\
\hline Не II $\lambda 6406$ & -0.288 & $\ldots$ & $\ldots$ & $0.32 \pm 0.03$ & $\ldots$ & $0.17 \pm 0.03$ & $\ldots$ & $\ldots$ \\
\hline [Ar v] $\lambda 6435$ & -0.292 & $\ldots$ & $\ldots$ & $2.58 \pm 0.04$ & $\ldots$ & $0.12 \pm 0.03$ & $4.52 \pm 0.19$ & $\ldots$ \\
\hline C II $\lambda 6462$ & -0.296 & $\ldots$ & $\ldots$ & $\ldots$ & $\ldots$ & $0.12 \pm 0.01$ & $\ldots$ & $\ldots$ \\
\hline He II + [N II $] \lambda 6527$ & -0.304 & $\ldots$ & $\ldots$ & $0.62 \pm 0.03$ & $\ldots$ & $0.17 \pm 0.01$ & $\ldots$ & $\ldots$ \\
\hline$[\mathrm{N}$ II $] \lambda 6548$ & -0.307 & $\ldots$ & $71.40 \pm 2.14$ & $186.43 \pm 1.49$ & $179.69 \pm 2.15$ & $0.50 \pm 0.01$ & $209.84 \pm 7.14$ & $7.23 \pm 0.04$ \\
\hline $\mathrm{H} \alpha \lambda 6562$ & -0.308 & $\ldots$ & $286.00 \pm 8.58$ & $286.00 \pm 2.28$ & $286.00 \pm 3.44$ & $\ldots$ & $286.00 \pm 9.78$ & $286.00 \pm 0.98$ \\
\hline [N II] $\lambda 6583$ & -0.311 & $0.85 \pm 0.01$ & $212.67 \pm 6.44$ & $566.03 \pm 4.55$ & $\ldots$ & $1.51 \pm 0.02$ & $646.88 \pm 22.31$ & $21.94 \pm 0.08$ \\
\hline He II $\lambda 6678$ & -0.323 & $3.36 \pm 0.01$ & $3.36 \pm 0.25$ & $3.04 \pm 0.04$ & $4.03 \pm 0.08$ & $2.59 \pm 0.02$ & $3.21 \pm 0.18$ & $3.53 \pm 0.04$ \\
\hline [S II] $\lambda 6717$ & -0.328 & $\ldots$ & $24.90 \pm 0.82$ & $7.484 \pm 0.07$ & $50.81 \pm 0.66$ & $0.24 \pm 0.01$ & $13.85 \pm 0.52$ & $1.74 \pm 0.04$ \\
\hline [S II] $\lambda 6731$ & -0.330 & $\ldots$ & $19.40 \pm 0.66$ & $9.75 \pm 0.09$ & $51.42 \pm 0.67$ & $0.26 \pm 0.01$ & $19.04 \pm 0.71$ & $2.83 \pm 0.04$ \\
\hline$c(\mathrm{H} \beta)$ & & 0.01 & 0.20 & 0.40 & 0.17 & 0.10 & 0.90 & 0.22 \\
\hline
\end{tabular}

